\title{
Assessment of speech the day after primary palate repair in 10 patients aged 11 to 36 years
}

\author{
David S Hayden MD, Donald H Lalonde MD MSc FRCSC, Marvin Hanson PhD \\ Division of Plastic Surgery, Dalhousie University, Saint John Regional Hospital, Saint John, \\ New Brunswick
}

\begin{abstract}
DS Hayden, DH Lalonde, M Hanson. Assessment of speech the day after primary palate repair in 10 patients aged 11 to 36 years. Can J Plast Surg 2000;8(5):181-184.

Ten previously unoperated cleft palate patients with ages ranging from 11 to 36 years underwent primary palate repair. Speech assessment was performed within $24 \mathrm{~h}$ before surgery, and then again within $24 \mathrm{~h}$ after surgery. Further follow-up was not possible. An overall improvement in speech was found the day after surgery in these adult primary palate repair patients.
\end{abstract}

Key Words: Adult; Cleft palate; Speech

\section{Évaluation de l'élocution le jour suivant une réparation primaire du palais chez 10 patients âgés de 11 à 36 ans}

RÉSUMÉ : Dix patients dont l'âge variait entre 11 et 36 ans et qui n'avaient jamais été opérés pour une fente palatine ont subi une réparation primaire du palais. Il y a eu évaluation de l'élocution $24 \mathrm{~h}$ avant l'intervention et $24 \mathrm{~h}$ après l'intervention. Un suivi plus long n'était pas possible. Dès le premier jour postopératoire, on a observé une amélioration générale de l'élocution chez ces patients adultes.

$\mathrm{I}_{\mathrm{p}}^{\mathrm{t}}$ $\mathrm{t}$ is generally considered that primary palate repair in adult patients does not generate a significant benefit in speech improvement after 12 years of age (1).

Primary repair has other possible benefits besides speech improvement. These include facilitated consumption of liquids and solids, facilitated oral and nasal hygiene, and an overall change toward normal function and appearance in the nasal and oral cavities.

Ten patients with previously unrepaired cleft palates had a primary palate repair during a volunteer surgical mission in Vietnam in November 1998. A speech language pathologist was present and carried out assessments of speech, just before and within $24 \mathrm{~h}$ after the primary palate repair. The goal of this study was to find out whether there were any immediate changes in speech as a result of the primary palate repair in these 10 patients.

\section{PATIENTS AND METHODS}

Patients were screened at a walk-in clinic in the city of Tra Vinh, Vietnam over a three-day period. History and physical examination were performed by four plastic surgeons. Speech assessment was performed by a non-Vietnamese-speaking American speech pathologist and an English-Vietnamese interpreter.

Inclusion criteria for the study were an unrepaired cleft palate of any variance and penetrance, an intact upper lip, and discernable deficits in speech as judged by the speech pathologist and interpreter. Patients were excluded if they had previous palate surgery or if they had other factors contributing to speech pathology.

Veau-Wardill-Kilner palate repairs were performed under general anesthesia by one of six American, Canadian or Vietnamese plastic surgeons with experience in cleft lip and

Correspondence: Dr Donald H Lalonde, 705 Millidge Avenue, Saint John, New Brunswick E2K 2N7. Telephone 506-648-7950, fax 506-652-8042,

e-mailhuzil@health.nb.ca 


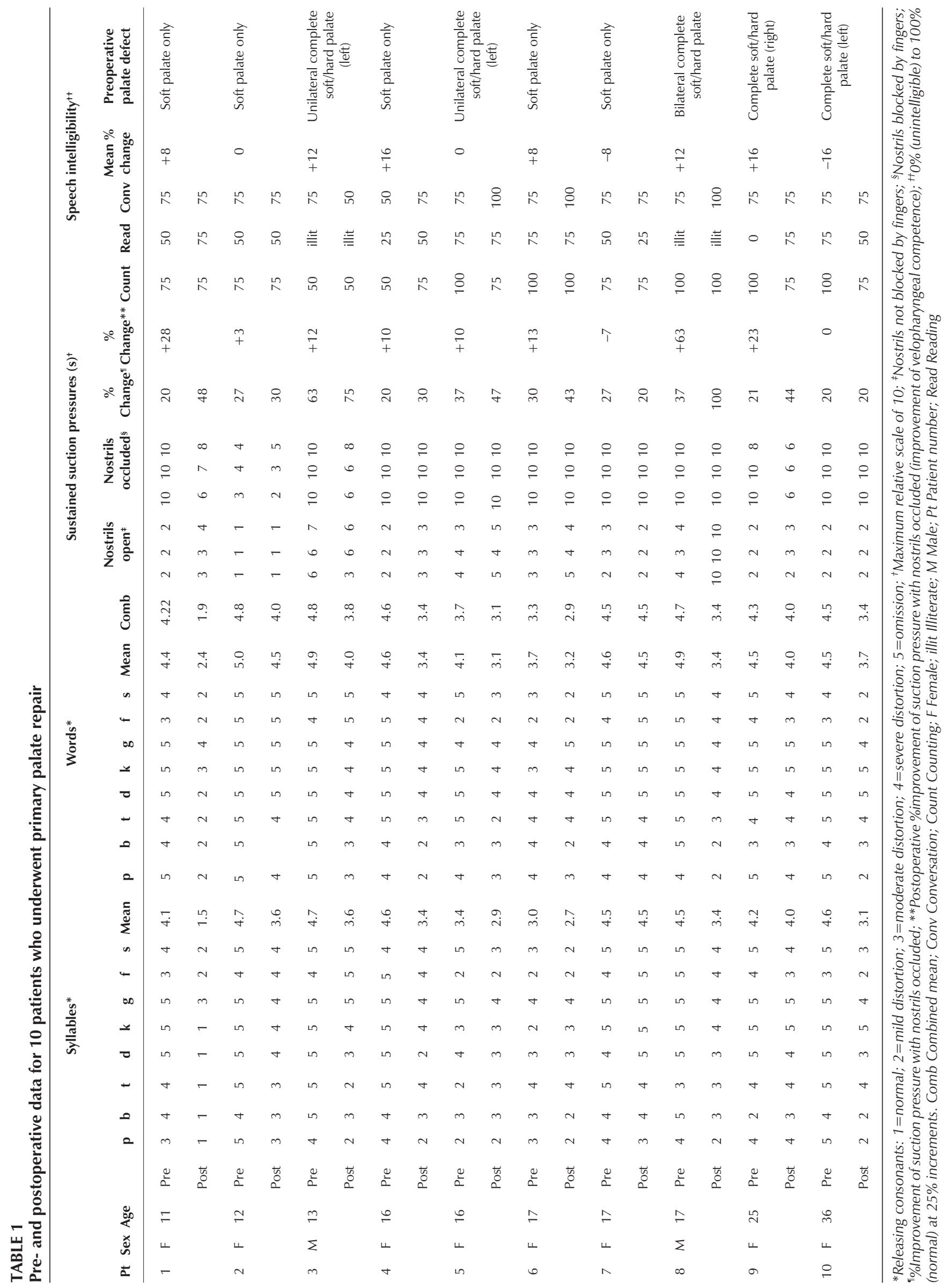


palte. Patients were admitted to the Tra Vinh hospital for overnight observation and discharged when stable.

Speech was assessed by the speech therapist both the day before surgery and on the first postoperative day on each patient who fit the inclusion criteria.

Subjects' performances were assessed in three general categories.

- Hanson judgments were graded on a five-point scale (Table 1) based on the patient's ability to form various releasing consonants as both syllables and short words.

- Hanson suction measurements were done with nostrils occluded and unoccluded to obtain a relative indication of sustained velopharyngeal (VP) closure. The instrument used was the Sea Scape (ProEd, USA). The patient puts the air tube in the mouth and sustains suction so that the floater attains its maximum elevation, and the suction power is measured on a relative scale from one to 10 , with the maximum possible number being 10. With normal VP competence, the number attained should be 10 with and without closure.

Improvement in VP closure was measured by dividing the total of the three suction pressure measurements with the nostrils open, by the total of the three suction pressure measurements with the nostrils occluded, and converting this into a percentage. The percent age change induced by the surgery was obtained by subtracting the postoperative improvement in VP closure from the preoperative improvement in VP closure.

- Overall speech intelligibility was assessed by a Vietnamese interpreter while having the patients count, read aloud and talk casually in their native tongue.

\section{RESULTS}

Of the 227 patients assessed in the clinic, 38 patients met the inclusion criteria for the study. There were 25 females and 13 males in this group. Ages of the patients ranged from seven to 50 years. The majority had complete cleft palates $(n=23)$ versus incomplete $(n=15)$.

Because of mission priority guidelines and time constraints, fewer than half of the available subjects were taken to the operating room. A total of 10 patients were successfully operated on and then screened both pre- and postoperatively. Several of the other patients who were operated on left before their postoperative assessment and were, therefore, excluded.

Of the 10 patients, eight were female and two were male. Ages ranged from 11 to 36 years. There were five soft palate repairs, four unilateral complete hard/soft palate repairs and one bilateral complete hard/soft palate repair.

Nine of the 10 patients demonstrated improvement in individual syllable production (Table 1). Mean improvement in all subjects was 1.2 for syllable production (on a scale of five) and 1.1 for word production. Mean improvement in
Hanson judgments for both words and syllables combined was 1.1 (range -1.1 to 2.3 ). Mean postoperative percentage improvement of suction pressure with the nostrils occluded (sustained VP closure) was 15.5\%.

On an individual basis, improvement in one section generally correlated with improvements in the other aspects of testing. Six patients showed improvements on the first postoperative day in all categories, and their ages ranged from the youngest to the second oldest patient treated (11 to 25 years of age).

Overall speech intelligibility was graded by a Vietnamese interpreter to have improved by a mean of $6 \%$ (range $-16 \%$ to $+16 \%$ ). Two patients, aged 17 and 36 years, showed deterioration in their assessments for 'overall intelligibility'. Two patients, aged 12 and 16 years, showed no change in overall speech intelligibility. Patient 10 showed no change in VP closure measurement and patient 7 showed deterioration of VP closure measurement after surgery. The other eight patients had a measurable improvement in VP closure measurement (Table 1).

\section{DISCUSSION}

In this study, the speech of 10 previously unrepaired cleft palate patients (ages 11 to 36 years) was studied just before and within $24 \mathrm{~h}$ after primary palate repair. An overall improvement in speech was found in most patients in the early postoperative period.

The ability of adults to incorporate new anatomy into speech has also been shown by Hall et al (2). They were able to produce normal speech in 15 of 20 adults who had cleft palate-related hypernasality who underwent pharyngeal flap surgery in adulthood. Brondsted et al (3) found similar results in Denmark.

Two other studies have looked at the results of late palate repair and have shown that it can be of some value in some patients, particularly if speech therapy is added to the palate repair (4). Sell and Grunwell (5) concluded that speech results following late palate surgery in previously unoperated adolescents is of no value unless it is followed by speech therapy. They cautioned that cleft palate repair should perhaps not be done in developing countries where no speech therapy is available (5).

In the first $24 \mathrm{~h}$ after surgery, there is a great deal of patient discomfort in attempting speech. In addition, all the errors of speech ingrained in the cerebellum are still present and the patients have not had the benefit of any form of speech therapy to even begin to overcome these errors. The fact that an improvement in speech was noted the day after surgery, in spite of the above obstacles, is indeed an interesting observation.

This study by no means justifies primary palate repair in adult patients for the purpose of improvement in speech. The lack of any long term follow-up and the small number of subjects could not justify such a conclusion. However, the findings were interesting and provide indications of improved capability of speech in these patients. 


\section{REFERENCES}

1. Ortiz-Monasterio F, Olmedo A, Trigos I, Yudovich M, Velazquez M, Fuente del Campo A. Final Results from the Delayed Treatment of Patients with Clefts of the Lip and Palate. Scan J Plast Reconstr Surg 1974;8:109-15.

2. Hall CD, Golding-Kushner KJ, Argamaso RV, Strauch B. Pharyngeal flap surgery in adults. Cleft Palate Craniofac J 1991;28:179-82.

3. Brondsted K, Liisberg WB, Orsted A, Prytz S, Fogh-Andersen P.
Surgical and speech results following palatopharyngoplasty operations in Denmark 1959-1977. Cleft Palate J 1984;21:170-9.

4. Landis P, Cuc T. Articulation patterns and speech intelligibility of 54 Vietnamese children with unoperated oral clefts, clinical observation and impressions. Cleft Palate J 1974;12:234-43.

5. Sell D, Grunwell P. Speech results following late palatal surgery in previously unoperated Sri Lankan adolescents with cleft palate. Cleft Palate J 1990;27:162-8. 